Theories \& Applications, the International Edition

Printed Version : (ISSN 2090-5262)

Online Version : (ISSN 2090-5270)

November 2014, Volume 4, No. 3 Pages (146 - 149)

\title{
Effect of Duration of Training and Body Weight on Bone Mineral Density in Female Athletes Practicing Taekwondo.
}

\section{Dr. Afaf Elsaied}

Faculty of physical education- Zagazig university, Egypt

\begin{abstract}
Genetic history, gender, diet, age, hormones and medications all play a big role in determining BMD. Active people generally have a higher bone mineral density $(B M D)$ when compared to their inactive counterparts and the type of exercise also has an impact on BMD. The aim of this investigation was to evaluate changes in bone mineral density at the hip and spine, among female athletes who practiced trained in taekwondo. The sample contained 19 female taekwondo players $(n=19)$, age 17-24. The sample was distributed amongst three groups, those who have participated in taekwondo training for 2-4 years $(n=6)$, those who participated in taekwondo training for 5-7 years $(n=7)$, and those who participated in taekwondo training for more than 7 years $(n=6)$. All participants completed questionnaires to assess their health history, physical activity, dietary intake, and menstrual history. Dual energy $x$-ray absorptiometry (DEXA) was used to assess bone mineral density $(B M D, \mathrm{~g} / \mathrm{cm} 2$ and $B M C, \mathrm{~g} / \mathrm{cm})$. Results indicated that there is a significant difference in BMD at the hip and spine for the group three. These results support the relationship between duration of training and BMD in female taekwondo players. In conclusion; participation in taekwondo has showed an increase in BMD.
\end{abstract}

Keywords: Bone Mineral Density, Training Duration, Taekwondo.

\section{Introduction}

$\mathrm{O}$ steoporosis is a disorder that affects the entire skeleton. It is characterized by a significant loss of bone mass leading to an increased susceptibility to fractures of the hip, spine, and wrist. It affects up to 24 million Americans, of which $80 \%$ are women. It is estimated that currently 10 million individuals already have osteoporosis, with 14 million more having low bone density (osteopenia). That means that approximately 1 in 4 women and 1 in 8 men have osteoporosis (Stevenson, et al. 1990).

In recent years, the utility of exercise to maintain bone health throughout life, and ultimately prevent osteoporosis related fractures, has been the subject of substantial research attention (Beck, 2003: Rutherford, 1999). However, evidence shows that not all exercise is equal when it comes to building strong, healthy bones or preventing osteoporosis. In fact, some forms of exercise may be linked to a decrease in bone density leading to bone loss and osteoporosis, even in elite athletes.

In 2009, researchers from the Bone \& Joint Injury Prevention \& Rehabilitation Center at the University of Michigan reviewed research as far back as 1961 to determine the impact exercise has on bone density and bone health.

They found three characteristics of the type of exercise that has the largest impact on increased bone density:

1. Strain magnitude of the exercise (This is higher in exercise such as gymnastics and weightlifting where the force or impact of the exercise is greatest).
2. Strain rate of the exercise (This is higher in exercise such as jumping or Plyometrics where the rate at which the impact is felt is high).

3. Strain frequency of the exercise (This is higher in exercise such as running, where the impact to the bones occurs frequently during the exercise session) (Manske, et al.2009).

The magnitude, rate and frequency of the strain during exercise all play a role in developing greater bone density; however, it remains to be determined which of the three is the most important.

Taekwondo, a Korean martial art, is a strenuous physical activity. Taekwondo may be recommended as a form of weight-bearing exercise to stimulate the osteogenic process and improve bone health. However, few investigators have evaluated the effects of taekwondo activity on bone health (Shin, et al.2011).

A number of studies have reported an association between body size and bone mass in adulthood (Cooper, et al. 1997: Fewtrell, et al.2000). Cooper et al. (1995) found significant correlations between weight at the ages of 1,5 , and 10 years and bone mineral content in the lumbar spine and the femur in adulthood. Blum et al. (2001) detected associations between weight and bone mineral density (BMD) of the lumbar spine and femur in women. Although taekwondo competitors are segregated by age and body weight, the effects of training duration on bone health during taekwondo practice have not been empirically determined.

Therefore, the aim of this investigation was to evaluate changes in bone mineral density at the hip and spine, among 
female athletes practicing taekwondo according to body weight

\section{Material and Methods}

\section{Participants}

Subjects included 19 female athletes practicing taekwondo, ages 17-24. The sample was distributed amongst three groups, Group 1 included those who have participated in taekwondo training for 2-4 years $(n=6)$, Group 2 included those who participated in taekwondo training for 5-7 years $(n=7)$, and Group 3 included those who participated in taekwondo training for more than 7 years $(n=6)$. Subjects and coaches were required to read and complete a health questionnaire that collected details of menstrual history and training status, as well as confirmed that there was no history of injuries, diabetes or recent surgery. Bone mineral density (BMD) in $\mathrm{g} / \mathrm{cm} 2$ of the 2nd 3rd and 4th lumbar vertebral bodies (LS) and the left hip (neck of femur, FN and trochanteric region, FT) was measured in each subject by dual energy X-ray absorptiometry (DXA) using a
Hologic QDR 1OOOW densitometer (Hologic Inc., Waltham, Mass. USA). Scan analysis was performed by technicians with daily experience in DXA analysis and who were blind to the menstrual status of the athlete. Current menstrual status was obtained from the reported numbers of menses in the preceding 12 months. All subjects were (10 to 12 cycles/year), the anthropometric characteristics are described in Table 1.

\section{Statistical Analysis}

All statistical analyses were calculated using the SPSS.V.16 (Statistical Package for the Social Sciences). The results are reported as means and standard deviations (SD). ANOVA analysis was used to compare the variation of the different variables between the three groups for regional bone. Least Significant Difference Test "LSD" was used to compare group means in variance analysis results which were found statistically significant. Differences in means were considered significant if $\mathrm{p}, 0.05$.

\section{Results}

Table 1

\begin{tabular}{|c|c|c|c|c|c|c|}
\hline Group & $\mathrm{N}$ & Age [years] & Weight $[\mathrm{kg}]$ & Height $[\mathrm{cm}]$ & BMI $\left[\mathrm{kg} / \mathrm{m}^{2}\right]$ & $\begin{array}{c}\text { Training } \\
\text { experience }\end{array}$ \\
\hline One & 6 & $19.24 \pm 3.2$ & $71.09 \pm 2.9$ & $171.00 \pm 6.1$ & $24.6 \pm 1.8$ & $3.3 \pm 1.5$ \\
\hline Two & 7 & $21.63 \pm 3.9$ & $77.54 \pm 3.1$ & $178.22 \pm 5.2$ & $24.1 \pm 2.1$ & $7.1 \pm 1.3$ \\
\hline Three & 6 & $22.74 \pm 4.5$ & $73.18 \pm 3.2$ & $172.17 \pm 6.8$ & $24.7 \pm 1.9$ & $8.0 \pm 2.1$ \\
\hline
\end{tabular}

Table 1 shows the age and anthropometric characteristics of the subjects. There were no significant differences observed in the anthropometric characteristics and age for the subjects in the three groups.

Table 2

$\mathrm{BMD}$ and Mean $\pm \mathrm{SD}$

\begin{tabular}{|c|c|c|c|c|c|c|c|}
\hline \multirow{2}{*}{ Skeletal Site } & \multirow{2}{*}{ Group 1 } & \multirow{2}{*}{ Group 2 } & \multirow{2}{*}{ Group 3 } & \multirow{2}{*}{ F test } & \multicolumn{3}{|c|}{ Percent difference\% } \\
\cline { 5 - 8 } & & & & & $1-2$ & $1-3$ & $2-3$ \\
\hline Fem Neck & $0.89 \pm 0.13$ & $0.93 \pm 0.14$ & $1.12 \pm 0.12$ & Sign & 3.5 & 22.8 & 19.3 \\
\hline Trochanter & $1.02 \pm 0.12$ & $1.12 \pm 0.13$ & $1.21 \pm 0.14$ & Sign & 8.6 & 17.1 & 8.5 \\
\hline Wards - tri & $1.06 \pm 0.13$ & $1.15 \pm 0.14$ & $1.25 \pm 0.11$ & Sign & 8.1 & 16.5 & 8.3 \\
\hline L2-L4 & $1.27 \pm 0.11$ & $1.38 \pm 0.17$ & $1.49 \pm 0.14$ & Sign & 8.3 & 15.9 & 7.7 \\
\hline
\end{tabular}

Table 2 shows the differences between BMD of hip and back spine for female athletes practicing taekwondo according to the duration of training. There were significant differences observed in the BMD for the subjects in the three groups.

Figure 1.

shows the differences between BMD of hip and back spine for female athletes practicing taekwondo according to the duration of training

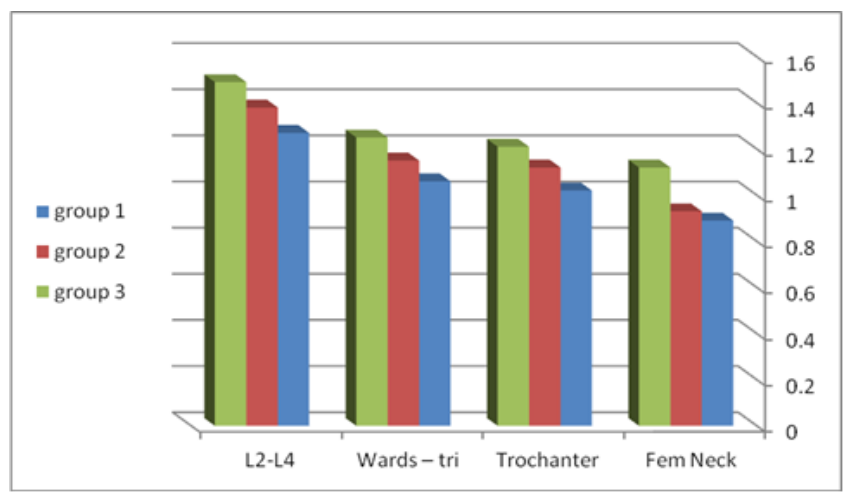


Figure 1 shows the differences between BMD of hip and back spine for female athletes practicing taekwondo according to the duration of training.

\section{Discussion}

The main findings from this study were the significant differences in the BMD of hip and back spine for those athletes that have trained for at least 7 years. After 7 years of taekwondo training the player get the black belt and the player will be ready to participate in the competitions. This finding indicated that the duration of training in taekwondo training has an influence on BMD.

During physical activity bones receive messages that they need to work and be strong. When there is a lack of exercise, bones do not receive these messages, which can result in lower bone mass. Regular physical activity on a long-term basis maintains the benefits for bone health (International Osteoporosis Foundation 2010). Weight bearing exercise has been shown to improve bone health in women. Several studies have demonstrated an association between vigorous exercise and BMD at various body sites (Karlsson, et al. 2008, Morris, et al. 1997, Petit, et al. 2007). It has been suggested that vigorous physical activity affects the skeleton, bone mineral content (BMC) and BMD in an anabolic manner (Hind \& Burrows, 2007). However, women in modern society are subjected to few daily biomechanical strains on their skeletal systems, and this may influence bone formation. In the current study, we determined the effects of the duration of training on BMD in the lumbar spine and hip in Egyptian female athletes practicing taekwondo.

According to Kim, (1995), Taekwondo is characterized as an activity where kicks compose 80 percent of the techniques. The basic kicks in taekwondo are front, crescent, roundhouse, side, back, and hook kick. All this movements requires jumps in continuously during training and competitions which will affected mechanically on bone mineral density .

These results agree with the results of previous studies which identified the types of exercise that confer maximal anabolic effects on the skeleton. The mechanical load required to stimulate osteogenesis decreases as strain magnitude and frequency increase (Cullen, et al.2001, Hsieh \& Turner, 2001). The osteogenic response to high magnitude loading saturates after a few loading cycles, after which additional loading has limited benefits (Karlsson, et al. 2008). Thus, high intensity sports such as squash, tennis, soccer, ice hockey, badminton, volleyball and weight-lifting are most effective when performed periodically, at different times during the week, if the aim is to improve skeletal strength (Karlsson, et al. 2008). Based on the results of these studies and the present study, we strongly recommend intermittent taekwondo activity to long term will increase BMD in women.

\section{Conclusions}

Long term taekwondo training significantly enhances bone health. Therefore, taekwondo activity is strongly recommended to improve bone health and prevent osteoporosis in women. Further well-designed investigations of the relationship between taekwondo activity and bone health across weights are warranted.

\section{References}

1. Beck BR, Snow CM. Bone health across the lifespan-exercising our options. Exerc Sport Sci Rev,2003;31 (3) :117-22.

2. Blum M, Harris S., Must A, Phillips S, Rand W, Dawson-Hughes B. Weight and body mass index at menarche are associated with premenopausal bone mass. Osteoporos. Int, 2001;12:588- 594.

3. Cooper C, Cawley M, Bhalla A, Egger P, Ring F, Morton L, Barker D. Childhood growth, physical activity, and peak bone mass in women. $J$ Bone Miner. Res, 1995;10:940-947.

4. Cooper C, Fall C, Egger P, Hobbs R, Eastell R, Barker D. Growth in infancy and bone mass in later life. Ann .Rheum. Dis. 1997;56(1):17-21.

5. Cullen DM, Smith RT, Akhter MP. Bone-loading response varies with strain magnitude and cycle number. J. Appl. Physiol. 2001;91:1971-1976.

6. Fewtrell, Prentice A, Cole TJ, Lucas A. Effects of growth during infancy and childhood on bone mineralization and turnover in preterm children aged 8-12 years. Acta. Paediatr. 2000;89(2):148153.

7. Hind K, Burrows M. Weight-bearing exercise and bone mineral accrual in children and adolescents: a review of controlled trials, Bone. 2007;40(1):1427.

8. Hsieh YF, Turner CH. Effects of loading frequency on mechanically induced bone formation. J. Bone. Miner. Res. 2001;16(5):918924.

9. International Osteoporosis Foundation 2010, available at http://testsite.iofbonehealth.org/docs/patientspublic/aboutosteoporosis/prevention/exercise.html

10. Karlsson MK, Nordqvist A, Karlsson C. Physical activity increases bone mass during growth. Food. Nutr. Res, 2008;52(10):1-10

11. Kim UY. Taekwondo textbook. Seoul: Oh-Sung Publishing Co.7,1995.

12. Manske SL, Lorincz CR, Zernicke RF. Bone Health: Part 2, Physical Activity. Sports Health: A Multidisciplinary Approach ,2009; 1:341-346.

13. Morris FL, Naughton GA, Gibbs JL. Carlson JS, Wark JD. Prospective ten-month exercise intervention in premenarcheal girls: positive effects on bone and lean mass. J Bone Miner. Res, 1997;12(9):1453- 1462. 
14. Petit MA, Hughes JM, Wetzsteon RJ, Novotny SA, Warren M. weight-bearing exercise and bone mineral accrual in children and adolescents: a review of controlled trials. Bone, 2007;41(5):903905.

15. Rutherford OM. Is there a role for exercise in the prevention of osteoporotic fractures? Br J Sports Med, 1999;33 (6) :378-86

16. Shin YH, Jung HL, Kang HY. effects of taekwondo training on bone mineral density of high school girls in Korea, Biol. Sport, 2011;28:195-198

17. Stevenson JC, Cust MP, Gangar KF, Hillard TC, Lees B, Whitehead MI. Effects of transdermal versus oral hormone replacement therapy on bone density in spine and proximal femur in postmenopausal women. Lancet, 1990; 4:336(8710): 265-9. 
